\title{
Uranium Uptake by Apatite at Hydrothermal Conditions
}

\author{
ANGEL JIMENEZ ${ }^{1}$, RINAT GABITOV ${ }^{1}$, ANH NGUYEN ${ }^{1}$, \\ DANIEL MAKOWSKY ${ }^{1}$, CHANAKA NAVARATHNA ${ }^{1}$, \\ TODD MLSNA ${ }^{1}$, VARUN PAUL ${ }^{1}$, ARTAS A MIGDISOV ${ }^{2}$ \\ AND ROBERT ROBACK ${ }^{2}$ \\ ${ }^{1}$ Mississippi State University \\ ${ }^{2}$ Los Alamos National Laboratory \\ Presenting Author: alj508@msstate.edu
}

Phosphate minerals are widely known not only for its common recurrence but also, for its versatility. Minerals of apatite group are known for their ability to host a number of radionuclides including uranium $(\mathrm{U})$. However, the quantitative relationships between dissolved $U$ and $U$ in the apatite at elevated temperatures are largely unknown. This work focuses on evaluating $U$ partitioning between phosphate minerals and fluid at hydrothermal conditions. The main objective of this work is to evaluate the role of phosphate minerals in immobilization of dissolved U. We precipitated synthetic brushite in powdered form. X-ray diffraction analysis was conducted to confirm brushite precipitation and its conversion to hydroxyapatite HAP. Brushite powder was placed into an autoclave with a $0.5 \mathrm{~mol} / \mathrm{l}$ of $\mathrm{NaCl}$ synthetic solution prepared in the laboratory. The solution was doped with aliquots of uranium-VI to make total concentrations ranging from 0.01 to $10 \mathrm{ppm}$. The experiments were loaded into a furnace at $200^{\circ} \mathrm{C}$ for 20 days. Experimental products (crystals and fluids) were analyzed for $U$ with inductively coupled plasma mass spectrometer (ICP-MS). The calculated partition coefficient $\left(\mathrm{D}^{\mathrm{U}}=\mathrm{U}_{\text {crystal }} / \mathrm{U}_{\text {solution }}\right)$ was found to be higher than 1000 . Based on simple mass balance assessment and obtained $\mathrm{D}^{\mathrm{U}}$ values, if concentration of dissolved $\mathrm{U}$ is $1 \mathrm{ppm}$, then crystallization of less than $1 \mathrm{~g}$ of phosphate would be required for removal of all $\mathrm{U}$ dissolved in $1 \mathrm{~kg}$ of solution at $200^{\circ} \mathrm{C}$. 